\title{
O REGIME DEMOCRÁTICO NO BRASIL: NOTAS PARA UMA AGENDA DE PESQUISA
}

Carlos Schmidt Arturi

\begin{abstract}
Resumo
O trabalho apresenta uma série de notas para uma agenda de pesquisa sobre a consolidação da democracia no Brasil, orientada pelas seguintes questões: o regime democrático em que vivemos tem sua consolidação ameaçada pelo descrédito institucional atual sobre sua representação, funcionamento e desempenho? Corremos o risco de perpetuação, ou mesmo agravamento, das condições de uma democracia política pouco eficaz em garantir os direitos civis da maioria da população? Estes dilemas dizem respeito a variáveis sociais, institucionais e culturais básicas para a legitimação do regime democrático-representativo. A análise foi centrada nos constrangimentos atuais ao regime democrático que encontram suas raízes no processo de transição e na tradição política do país, onde se destacam a grande desigualdade social ainda vigente e a violência crescente, que provocam graves efeitos políticos, tais como o encolhimento da comunidade política e a dificuldade de manutenção do Estado de Direito democrático.
\end{abstract}

Palavras-Chave: Transição Política; Consolidação da Democracia; Desigualdade Social; Violência.

\begin{abstract}
The paper presents a series of notes for a research agenda about democracy consolidation in Brazil, guided by the following questions: the democratic system where live has it consolidation threatened by current institutional discrediting on its representation, functioning and performance? We run the risk of perpetuating, or even worsening, of the conditions of a political democracy less effective in guaranteeing the civil rights of the population's majority? These dilemmas relate to social, institutional and cultural basic variables to the legitimacy of the representative democratic regime. The analysis was focused on the constraints to the current democratic regime that have their roots in the transition process and the political tradition of the country, where features the great social inequality that is still in force and the increasing violence, which cause serious political effects like as shrinkage of the policy community and the difficulty of maintenance the democratic rule of law.
\end{abstract}

Keywords: Political Transition; Democracy Consolidation; Social Inequality; Violence.

\section{Introdução}

A dualidade analítica quase onipresente na literatura política e sociológica elaborada durante a ditadura opunha os termos Estado e Sociedade Civil, conceitos que denotavam a dominação autoritária para o primeiro termo e considerava a sociedade civil como fonte, como conjunto das forças democráticas de resistência. Visão simplificadora e conveniente para 
aqueles tempos, mas insuficiente para a análise da situação atual, onde se comemora mais duas décadas de regime democrático, período já mais longevo do que a República democrática liberal de 1946-1964. Regime democrático que sobreviveu a uma série provações: crise econômica aguda; impeachment de um presidente da República; revisão constitucional, que incluía plebiscito sobre forma de governo; e a eleição de dois candidatos de esquerda à presidência da República.

Todavia, atualmente, a carga de negatividade atribuída ao Estado nas análises durante a Ditadura foi transferido, no senso comum, para o sistema político como um todo (instituições, partidos, lideranças políticas, do governo e da oposição). No que concerne ao termo Sociedade, este se encontra atualmente mais nuançado nas análises e nas evocações políticas: lugar dos movimentos democráticos, mas também dos conservadores e autoritários, à direita e à esquerda do espectro político. Se, em meados de 2005, podíamos dizer que o governo e parte das forças parlamentares envolvidas no chamado mensalão estavam em crise, hoje, é o conjunto da representação nacional que se encontra em profundo descrédito por boa parte da população.

Com efeito, os reflexos desta situação podem ser aferidos por medidas atitudinais a respeito do desempenho da democracia no Brasil, como os dados do Latinobarômetro que, em 2004, revelavam que somente $28 \%$ dos entrevistados brasileiros estavam satisfeitos com a democracia, enquanto apenas $41 \%$ consideravam esta forma de governo superior a qualquer outra (sendo que este percentual atingia $78 \%$ no caso do Uruguai). Este índice para - Brasil havia caído $9 \%$ em relação a 1996 . Pesquisa encomendada pela Associação dos Magistrados Brasileiros, em 2007, revelava que a Polícia Federal e as Forças Armadas eram consideradas as instituições mais confiáveis, com aprovação de $75 \%$ dos entrevistados, em contraste com $42 \%$ de aprovação para o Judiciário e de apenas $16 \%$ de aprovação para os partidos políticos. Os sucessivos escândalos da vida política nacional, que ocorreram daquela época até o início de 2011, amplificados por uma cobertura jornalística não raro sensacionalista e tendenciosa, não melhoraram este amplo quadro de descrédito em relação ao sistema político nacional.

Estes fatores deletérios ao aperfeiçoamento democrático ocorrem justamente em uma época de crescimento econômico e de melhorias significativas na distribuição de renda e de diminuição da pobreza absoluta. Persistem, entretanto, ainda níveis extraordinariamente altos de concentração de renda e de exclusão social, de violência e de desrespeito aos direitos civis e humanos da parcela mais pobre da população, o que demonstra a complexidade e os riscos para a consolidação e aprofundamento do regime democrático no país. Aqui, desde logo, adota-se o entendimento de regime democrático como sinônimo de Poliarquia, tal como caracterizada por Dahl (1997). Sabemos que uma definição minimalista do regime democrático está longe de obter unanimidade na literatura, mas a definição da democracia como regime político, cuja base fundamental é a livre competição pacífica 
pelo poder e a garantia das liberdades civis fundamentais, possui grande capacidade operatória no domínio da pesquisa (HUNTINGTON, 1991).

É justamente em referência a esta zona de sombras da atual conjuntura que foram elaboradas uma série de notas para uma agenda de pesquisa sobre a consolidação da democracia no Brasil. Para adiantar as questões principais: o regime democrático que vivemos tem sua consolidação ameaçada pelo descrédito institucional atual sobre sua representação, funcionamento e desempenho? Corremos o risco de perpetuação, ou mesmo agravamento, das condições de uma democracia política pouco eficaz em garantir os direitos civis da maioria da população? Ou mesmo de uma morte lenta do regime democrático no país, tão duramente conquistado? Estas questões dizem respeito a variáveis sociais, institucionais e culturais básicas para a legitimação do regime democrático-representativo.

O deslocamento do interesse das pesquisas da fase da transição política para a problemática da consolidação da democracia acelerou-se quando a instauração deste tipo de regime se revelou mais auspiciosa do que inicialmente previsto pelos especialistas. Neste momento, emerge uma crítica aos limites da democracia política e/ou as chances de sua consolidação na ausência de profundas reformas econômicas e sociais. Estes questionamentos centram-se quer nas limitações propriamente políticas do regime democrático - delegativas, cidadania de baixa intensidade (O'DONNELL, 1993 e 1994), low democracy, (GILLS e ROCAMORA, 1992), liberalismo democrático (NUN, 1992) - quer definindo da democracia através de variáveis socialmente substantivas, isto é, como um tipo de sociedade específica (democracia social, democracia popular, etc.). Ora, a consideração de variáveis sociais, econômicas e culturais (alto grau de desigualdade social, crise econômica, cultura política autoritária, transformação do papel do Estado, ofensiva ideológica neoliberal, etc.) é pertinente, sobretudo, para a identificação dos dilemas e constrangimentos à consolidação da nova ordem política. Com efeito, a consolidação da democracia é uma espécie de segunda transição e a avaliação da estabilização e enraizamento deste regime em um determinado país requer um considerável recuo temporal (MORLINO, 1992).

\section{Constrangimentos à consolidação do regime democrático que possuem sua origem no processo de transição política}

Os constrangimentos à consolidação do regime democrático têm sua origem mais imediata no modo de transição e nas ações dos atores políticos na atual conjuntura nacional, sem ignorar os problemas derivados de características mais duradouras e estruturais do sistema político e institucional brasileiro, que não serão objeto privilegiado destas notas. A literatura especializada destacou a forte afinidade que existiria entre o modo de transição e os dilemas para a consolidação da democracia (O'DONNELL e SCHMITTER, 1988). Nesta perspectiva, os acordos políticos e os arranjos institucionais estabelecidos durante os processos de transição são 
responsáveis pela configuração das condições iniciais do novo regime democrático. De fato, a maneira pela qual a democracia é instalada não determina totalmente seu desenvolvimento posterior, mas estabelece as regras do jogo, as modalidades de interação entre os atores e os limites às mudanças políticas. Na transição brasileira, o gradualismo, o continuísmo político e o controle exercido pelos detentores do poder legaram resíduos autoritários e reforçaram práticas políticas tradicionais do país que constrangem o processo de consolidação do novo regime democrático a partir de 1990 (ARTURI, 2001).

Nesta perspectiva, a interação entre a estrutura econômica, social e política pré-existente e a estratégia dos atores políticos permitem arranjos institucionais e comportamentais que condicionam as possibilidades de uma consolidação democrática. Por exemplo, os acordos entre os militares e a oposição, estabelecidos na fase de liberalização política, podem persistir longamente, originando uma democracia com defeitos de nascença (KARL e SCHMITTER, 1991). Desta maneira, traços da cultura política de um país, comportamentos historicamente arraigados e constrangimentos estruturais podem, ou não, ser reforçados pelas escolhas e ação dos atores políticos em uma determinada conjuntura. Identificamos no conceito de democracia delegativa, que refere-se aos regimes da terceira onda de democratizações que são "intrinsecamente hostis aos padrões de representação normais das democracias estabelecidas, à criação e consolidação das instituições políticas e, especialmente, à 'prestação de contas horizontais' [accountability]" (O'DONNELL, 1993, p. 165, grifos do autor), um exemplo de fenômeno deste tipo. Os elementos plebiscitário e personalista das democracias delegativas teriam suas origens no estilo populista e na baixa institucionalização que marcaram o passado político da América Latina.

Outra ilustração eloquente da influência da história política em conjunturas específicas concerne à democratização brasileira. Com efeito, a longa duração e a evolução extremamente gradual da fase de liberalização política, assim como a utilização da competição eleitoral como recurso institucional privilegiado da transição, criaram no mundo político brasileiro uma percepção de normalização do processo conduzido sob o controle e segundo as regras impostas unilateralmente pelos detentores do poder. Estas regras foram como que naturalizadas nas avaliações, cálculos e elaboração de estratégias pelos principais atores políticos ao longo do período (LAMOUNIER, 1985 e 1988). Este fator tempo revelou-se fundamental para o alargamento progressivo do setor moderado da oposição e daquele reformista do regime. Assim, a perda de controle sobre a transição, ao final da presidência Figueiredo (1979-1985), significou a autonomização da lógica deste processo (LESSA, 1989), originado por uma estratégia voluntarista dos dirigentes do regime e modelado pelas características mais tradicionais da vida política brasileira: uma praxis autoritária associada a uma lógica liberal (TRINDADE, 1985), a centralidade política dos militares e a tradição de conciliação pelo alto das elites políticas. Estas características conformam, em parte, uma 
cultura política que torna o sistema político brasileiro resistente tanto a ditaduras clássicas quanto a sua democratização estável (LAMOUNIER, 1988).

Aqueles países que sofreram um longo período de autoritarismo sob a direção dos militares devem ainda, segundo Alain Rouquié (1994), satisfazer duas condições políticas indispensáveis à consolidação da democracia, além dos requisitos minimalistas: 1) a real possibilidade de alternância das forças políticas no poder; 2) o efetivo controle civil sobre os militares. Ora, no caso brasileiro, a primeira condição foi satisfeita com a eleição e reeleição de Lula à presidência da República, mas o controle civil sobre os militares ainda está por ser testado. Ademais, e consideramos ser esta uma terceira condição para consolidação da democracia, a efetividade do estado de Direito democrático para a maioria da população está muito longe de ser alcançado.

Examinemos melhor estas condicionalidades. Em termos estritamente políticos, a consolidação da democracia exige que a incerteza em relação à competição pelo poder torne-se aceitável para os principais atores políticos (PRZEWORSKI, 1984), em outras palavras, que eles concordem que os vencedores de eleições, independentemente de quem sejam, assumam os níveis de poder que estavam em disputa. O único e breve período parlamentarista no Brasil (1961-1963), adotado para evitar um veto militar à posse de João Goulart na Presidência da República, constitui um exemplo muito ilustrativo de uma situação de um regime democrático diminuído, pois os poderes constitucionais do presidente da República, quando das eleições de 1960, foram reduzidos entre setembro de 1961 e janeiro de 1963. Neste caso, o parlamentarismo foi uma solução de compromisso entre o veto dos militares à posse de Goulart com poderes presidenciais integrais e o sucesso de um movimento de resistência à tentativa do golpe militar, capitaneado pelo governador do Rio Grande do Sul, Leonel Brizola, a Campanha da Legalidade. Mais recentemente, alguns observadores políticos enxergaram no plebiscito sobre a forma de governo (presidencialista ou parlamentarista), ocorrido em 1993, por disposição transitória da Constituição de 1988, uma salvaguarda das forças mais conservadores para a eventualidade de uma vitória das esquerdas na eleição presidencial de 1989.

Entretanto, a importante contribuição de Przeworski para a identificação deste elemento central das regras do jogo democrático - a incerteza - deve ser relativizada. De fato, a incerteza quanto aos resultados da competição política só é aceitável para os antigos dirigentes do regime autoritário e para as classes dominantes, se vier acompanhada de outras certezas que restringem o alcance de eventuais reformas econômicas, sociais e políticas que possam ser implementadas pela antiga oposição quando alcançam o poder pelas urnas. Foi o caso da Carta aos brasileiros, assinada pelo então candidato à presidência Luís Inácio Lula da Silva, no segundo semestre de 2002, comprometendo-se a continuar basicamente com a política econômica de seu antecessor, Fernando Henrique Cardoso, entre outras medidas conciliatórias em relação ao eleitorado centrista. Esta garantia 
política fornecida por Luís Inácio Lula da Silva se revelou fundamental para sua vitória eleitoral daquele ano para a presidência da República.

Assim, os acordos que favorecem uma transição pactada - moderação e objetivos minimalistas da oposição - revelam-se, posteriormente, obstáculos e constrangimentos para a consolidação da democracia. Isto é, o abandono daquelas instituições e arranjos que facilitaram a transição, mas que são consideradas antidemocráticos, torna-se pouco viável após a democratização. Como exemplo, as atuais prerrogativas constitucionais e o poder informal dos militares brasileiros ainda são muito amplos, embora declinantes, o que thes proporcionou um alto grau de autonomia em relação ao aparelho de estado e uma forte influência sobre o processo de constituição da nova ordem democrática. Como afirma Zaverucha (2000 e 2005), os militares continuam a supervisionar os governos civis em assuntos de seu interesse, sem almejar tomar o poder, mas com poder de veto em momentos de crise política aguda. As sucessivas quedas de ministros da defesa, em particular a de José Viegas, e os episódios da crise da aviação civil bem o demonstram. É significativo que a posse de Nelson Jobim como Ministro da Defesa, que exerce suas funções com autoridade e vontade reformista, tenha sido considerada por Luiz Felipe de Alencastro, em artigo de 2007, como o último episódio da transição democrática ${ }^{1}$.

O processo de democratização no Brasil possui ainda um aspecto inacabado: a sobrecarga da agenda econômica e social da Constituinte - em razão da ausência de pactos substantivos entre os atores sociais no período anterior de liberalização política, como ocorreu na Espanha com o Pacto de Moncloa - não permitiu a regulamentação de muitos dos princípios políticos e econômicos contemplados pela nova Carta, remetidos para a regulamentação posterior através de leis ordinárias. Portanto, o intenso ciclo de mobilização política democratizante, a partir das Diretas-Já, ainda não resultou em reforma institucional que o encerrasse (RODRIGUES, 2001). Pelo contrário, entre 1988 e 2003, foram apresentadas 44 emendas constitucionais e outras 500 tramitam no Congresso. Ou seja, não possuímos ainda estabilidade legal, sem a qual não há fixação das regras do jogo político, o que resulta, em termos práticos, que o poder Judiciário passe a crescentemente desempenhar funções legislativas (lei eleitoral, união homo-afetiva, etc.).

Em relação aos fatores concernentes à fragilidade do sistema partidário que deitam suas raízes na história política do país, destacam-se a estreita dependência dos partidos em relação ao Estado. Nesta perspectiva, um dos constrangimentos mais duráveis à democracia oriundos do golpe de 1964 foi, justamente, a interrupção do sistema partidário do período 1945-1966 que demonstrava uma tendência de forte identificação eleitoral. Outro obstáculo herdado deste período foi a centralização do poder no Executivo, com a

\footnotetext{
${ }^{1}$ Disponível em:

<http://www.fazenda.gov.br/resenhaeletrônica/MostraMateria.asp?page=\&cod=404274>. Acesso em: 30 abr. 2011.
} 
consequente manutenção até os dias de hoje de um Legislativo reativo, para utilizar uma expressão de Fabiano Santos.

Outro fator importante originado pelo modo de transição para a democracia no Brasil, que problematiza até hoje sua consolidação, foi o fato de que aquele processo se desenvolveu prioritariamente através de acordos entre a oposição e as lideranças do regime no seio do Congresso, arena privilegiada da transição, mas com pouca ligação com a sociedade civil. Houve na transição brasileira, segundo Renato Lessa (1989), uma dissociação entre Demos e Polis, entre sociedade civil e sociedade política. Nesta perspectiva, a única possibilidade, em mais de uma década de liberalização política, que poderia ter resultado numa ruptura institucional com o antigo regime - no início de 1984, quando se desenvolveu a grande campanha por eleições diretas para presidente da República - foi abortada porque os principais atores políticos já estavam satisfeitos com legalidade autoritária. Assim, a opção dos atores mais relevantes neste período reforçou a tradição brasileira de conciliação pelo alto, a utilização da competição eleitoral para mensurar o poder dos dirigentes face a seus opositores e a presença dos militares como um dos atores centrais no sistema político (ARTURI, 2000).

Nesta perspectiva, o caso brasileiro confirma a hipótese da path dependency, isto é, uma vez adotado determinado padrão institucional, ele tende a estabilizar-se e a enquadrar a atividade política. A possibilidade de modificações significativas na tradição política e no padrão institucional de um país dar-se-ia em certas conjunturas críticas, como é o caso dos processos de transição de regime (HUNTER, 1997). Ora, a investigação empírica da liberalização do regime autoritário no Brasil permite qualificar melhor esta proposição, ao demonstrar que naqueles processos de transição que se realizam de forma muito gradual e controlada, as mudanças de regime político podem ocorrer sem alterações importantes no padrão institucional e nas práticas políticas tradicionais.

Ocorreram também alterações significativas na hierarquização do valor explicativo das variáveis segundo a fase do processo de democratização. $O$ foco temático das pesquisas deslocou-se das condições de emergência das transições - crise dos regimes autoritários, causas da liberalização política, alianças e conflitos entre atores - para os dilemas relativos à consolidação da democracia - prerrogativas militares, construção de instituições democráticas, reforma do estado sob conjunturas de grave crise econômica, etc. Durante a transição propriamente dita do regime autoritário à democracia, as variáveis mais influentes seriam aquelas concernentes à qualidade da ação dos atores políticos e à interação de suas estratégias. Inversamente, após a instauração do regime democrático, as variáveis macro-sociais (nível de desigualdade social, tipo de política econômica, influência de fatores internacionais, grau de reforma do estado, etc.), institucionais (sistema de governo, sistema eleitoral-partidário, etc.) e de cultura política constituiriam as mais importantes para o sucesso ou fracasso da consolidação do novo regime. 
Neste sentido, Nohlen e Thibaut afirmam que os maiores problemas para a consolidação do regime democrático não se originam da crise econômica ou das contradições entre pactos de elite e demandas sociais por reformas, mas de mecanismos institucionais, tais como a relação entre executivo e legislativo ou a perda de capacidade de agregação e representação dos sistemas políticos (NOHLEN e THIBAUT, 1994, p. 26).

Talvez, o efeito político de caráter mais estrutural legado pela transição até os dias de hoje foi o de que a instalação de regimes democráticos na maioria dos países latino-americanos, a partir da década de 1980, coincidiu com o esgotamento do modelo nacional-desenvolvimentista e, no Brasil, com as profundas reformas do Estado - desestatização e privatização implantadas desde as presidências Collor a Lula. Este característica de duplatransição (SALLUM, 1996) teve efeitos deletérios para a incorporação social de vastos contingentes da população (SANTOS, 2006), o que problematiza sobremaneira a qualidade do regime democrático. De fato, a capacidade de um Estado é condição para a democracia. Sem uma adequada capacidade institucional de fazer valer as regras e implementar as decisões tomadas pelos sujeitos políticos, ou sem a capacidade de garantir o cumprimento dos direitos e deveres associados à cidadania, a democracia continua frágil.

Aos dilemas políticos para a consolidação da democracia que se originaram do processo de transição, devem, portanto, ser acrescentados aqueles concernentes à desigualdade social, bem como os decorrentes da profunda mudança no papel do Estado, pela qual passa atualmente a sociedade brasileira. Passamos, agora, aos dilemas propriamente atuais para a consolidação do regime democrático no país e que podem constituir, isolada ou agregadamente, temas para pesquisas sobre a consolidação da democracia no Brasil, objetivo destas notas.

\section{Notas para pesquisas sobre os atuais dilemas para a consolidação do regime democrático}

Aos constrangimentos políticos para a consolidação da democracia que se originaram do processo de transição, devem ser acrescentados aqueles que concernem à desigualdade social, bem como os decorrentes da profunda mudança no papel do Estado no Brasil, durante as últimas décadas. Este conjunto de fatores problemáticos para a consolidação do regime democrático no país constitui uma agenda de pesquisa sobre o tema, embora não o esgote, e cujos pontos principais são apresentados a seguir.

Institucionais. Do ponto de vista propriamente institucional, o protelamento constante de uma reforma política que fortaleça o sistema partidário (186 parlamentares federais, entre 608 titulares e suplentes, mudaram de partido na legislatura 2003-2007), agrava o desempenho e a imagem das instituições e lideranças políticas. A judicialização da política, por sua vez, altera o equilíbrio entre poderes, em detrimento do Congresso. A corrupção ligada ao financiamento de campanhas e ao aliciamento de partidos 
e parlamentares fisiológicos não é novidade no Brasil, nem nas democracias dos países avançados, mas o que causa estupor é sua utilização recorrente para obtenção de maiorias parlamentares, que aumenta o distanciamento entre a sociedade civil e a política. Estes temas, embora bastante estudados, ainda merecem análises complementares que os vinculem com a consolidação do regime democrático.

Experiências participativas. É necessário estudar mais as experiências políticas democráticas alternativas, como aquelas dos orçamentos participativos, diversas formas de conselhos, etc. Estes experimentos institucionalizados no Brasil podem servir de complemento aos mecanismos políticos típicos das democracias representativas e atrair para a arena pública uma parcela da população desencantada com as práticas políticas tradicionais.

Cultura política. Outro ponto da pauta de uma agenda de pesquisa sobre a democratização deve buscar a compreensão do processo pelo qual os atores políticos e sociais estruturam suas crenças e representações a respeito da política (BAQUERO, 2011; MOISÉS, 1995). No Brasil, a adesão à democracia por boa parte da população é ainda frágil, o que dificulta sua consolidação. É necessário, portanto, aprofundar e expandir os estudos sobre a cultura política nacional, área que se encontra, atualmente, subrepresentada na literatura especializada no país.

Direitos civis e direitos humanos. Todavia, é na inefetividade do Estado de Direito democrático para boa parte da população, explicitada pela violência generalizada e pela falência da segurança pública, que reside, em nosso entender, a maior ameaça à consolidação do regime democrático no país. Inefetividade e violência que atinge primordialmente os mais pobres, com a proliferação de milícias e indícios de execuções sumárias no combate ao crime. Com efeito, o Estado não consegue exercer o monopólio da violência e impor a ordem política democrática no conjunto do território nacional. Por sua vez, as agências estatais resistem em atender com equidade e reconhecer os direitos da população mais pobre e das minorias sociais; especialmente os órgãos de segurança pública, que persistem no emprego de métodos arbitrários e violentos sobre estes setores. A grande concentração da renda no Brasil provoca indiretamente graves efeitos políticos, tais como o encolhimento da comunidade política, a dificuldade de manutenção da ordem pública, a falta de confiança nos políticos, fatores que minam a legitimidade do regime democrático em longo prazo (REIS e CHEIBUB, 1993).

No caso brasileiro, este padrão de atuação, desrespeitoso com os direitos humanos fundamentais, tem sua origem mais remota no passado escravista do país, mas foi reforçado pelo longo período autoritário. O’Donnell utiliza-se do conceito de democracia iliberal para descrever a situação na qual "se respeitam os direitos participativos e democráticos da poliarquia, mas se viola o componente liberal da democracia. [...] Esta bifurcação constitui o reverso da moeda da complexa mescla de componentes democráticos e autoritários nestes estados" (O'DONNELL, 1993, p. 173). 
Segurança Pública. Estudos comparados poderão melhor qualificar os constrangimentos à consolidação dos novos regimes democráticos (MARENCO, 2007), sobretudo no que se referem à institucionalização dos serviços de inteligência e de segurança interna, com legitimidade e sob controle democrático. O problema crucial do tema em análise é a tensão, sempre existente nos regimes democráticos, entre as funções coercitivas das organizações de segurança pública e as liberdades e direitos civis dos cidadãos, bem como entre as necessidades do segredo das funções de inteligência e os controles democráticos de suas atividades (accountability) (CEPIK, 2005). Especialmente nos países da terceira onda de democratizações, seus atuais órgãos de inteligência e de segurança interna são, frequentemente, herdeiros daqueles que operavam durante as ditaduras, vinculados à repressão política. Assim, o amálgama entre segurança pública e segurança nacional, entre inimigo externo e interno, bem como o baixo controle exercido pelas instituições políticas sobre as atividades e a regulamentação dos serviços de inteligência e de manutenção da ordem interna, impregnou os passos iniciais da institucionalização destas organizações na maioria dos países recentemente democratizados, frequentemente com efeitos deletérios sobre as liberdades civis.

Nesta perspectiva, como estão constituídos e atuam seus sistemas de inteligência e de segurança interna? Qual o grau de controle político democrático sobre as organizações de inteligência e de segurança? Qual o padrão das relações entre civis e militares? Os limites, as atribuições, os mandatos legais e a coordenação destes órgãos estão claramente definidos? As instituições políticas e civis de controle e supervisão destas atividades, particularmente o Legislativo e suas comissões especializadas, possuem recursos e mandato legal para exercer a contento suas funções no regime democrático? As respostas a estas questões são essenciais para avaliar a constituição de atores com prerrogativas políticas incompatíveis com a responsabilização política democrática.

Conjuntura internacional. A Guerra Antiterror, por sua vez, provocou a erosão da distinção entre inimigo externo e interno, o continuum entre crime comuns e crimes políticos e/ou terroristas, a militarização da segurança pública, bem como a terceirização e justificação da tortura até mesmo nas velhas democracias avançadas. As incertezas da política internacional e potenciais conflitos regionais nos trazem fumos de uma Guerra Fria, diferente da de outrora, mas não menos problemática para a manutenção da democracia nos países periféricos.

\section{Balanço e perspectivas de pesquisa}

As considerações aqui realizadas centraram-se nos constrangimentos atuais ao regime democrático que encontram suas raízes no processo de transição e na tradição política do país. Dentre os óbices apontados, destacase a grande desigualdade social ainda vigente e a violência crescente, que 
provocam graves efeitos políticos, tais como o encolhimento da comunidade política, a dificuldade de manutenção do Estado de Direito democrático sobre todo o território nacional e para todas as classes sociais, a continuidade do assistencialismo e do clientelismo, fatores que minam a legitimidade do regime democrático em longo prazo. Ou seja, o desafio é o da superação da contradição entre inclusão política, plenamente alcançada, e o da exclusão social (WERNECK VIANNA, 2006). Este, no nosso entender, é o verdadeiro teste de fogo da consolidação da democracia no país.

Não se desconsidera aqui os progressos obtidos nos últimos anos, em termos de desconcentração de renda, diminuição da pobreza absoluta e, pela primeira vez, uma genuína inclusão dos pobres na agenda política e social do governo. Mas, o problema é de tempo político. Em outras palavras, até quando regime democrático se sustenta, sem se descaracterizar, face ao forte descrédito das instituições políticas, mesmo que nenhum ator relevante queira sua derrubada? Até quando pode ser mantido um regime democrático efetivo sem atores relevantes que o valorizem?

As perspectivas políticas em médio prazo no que concerne ao regime democrático no país são, portanto: 1) a permanência do regime democrático iliberal, devido à ausência de profundas reformas econômicas e sociais e nos aparatos de manutenção da ordem interna; 2) melhoria sustentada da incorporação social dos mais pobres e da representação política (versão mais otimista); ou, 3) aprofundamento da violência e do conflito social em um quadro de descrédito das instituições (possibilidade de retrocesso, de baixa probabilidade). Em suma, a consolidação da democracia no país ainda é apenas uma possibilidade alvissareira e as notas acima apresentadas sugerem um caminho para pesquisas futuras que tenham este tema como centro de suas preocupações.

Carlos Schmidt Arturi é Professor Associado do Departamento de Ciência Política da UFRGS, Doutor em Ciência Política pelo Institut d'Etudes Politiques de Paris (Sciences Po) e Pós-Doutor pelo Instituto de Ciências Sociais (ICS) da Universidade de Lisboa (2005), Bolsista Produtividade Nível 2 do CNPq.

E-mail: carlos.arturi@ufrgs.br

\section{Referências}

ARTURI, Carlos S. Le Brésil: une tentative de démocratisation octroyée (19741985). Villeneuve d'Ascq: Presses Universitaires du Septentrion, 2000.

. O Debate sobre Mudança de Regime Político à Luz do Caso Brasileiro. Revista de Sociologia e Política, Curitiba, n. 17, p. 11-31, nov. 2001.

BAQUERO, Marcello (Org.). Cultura(s) Política(s) e democracia no Século XXI na América Latina. Porto Alegre: Editora da UFRGS, 2011. 
CEPIK, Marco. Regime Político e Sistema de Inteligência no Brasil: legitimidade e efetividade como desafios institucionais (1999-2004). Dados, Rio de Janeiro, v. 48, n. 1, p. 67-113, jan.-mar 2005.

DAHL, Robert. Poliarquia: Participação e Oposição. São Paulo: Editora da USP, 1997.

GILLS, Barry; ROCAMORA, Joel. Low intensity democracy. Third World Quarterly, Londres, v. 13, n. 3, p. 501-523, 1992.

HUNTER, Wendy. Eroding Military Influence in Brazil: Politicians against Soldiers. Chapel Hill/London: University of North Carolina Press, 1997.

HUNTINGTON, Samuel. The Third Wave: democratization in the late twentieth century. Norman: University of Oklahoma Press, 1991.

KARL, Terry; SCHMITTER, Philippe. Les modes de transition en Amérique latine, en Europe du Sud et de l'Est. Revue Internationale des Sciences Sociales, Paris, n. 128, p. 285-302, mai 1991.

LAMOUNIER, Bolívar. Apontamentos sobre a questão democrática brasileira. In: ROUQUIÉ, Alain; LAMOUNIER, Bolívar; SCHWARCZ, Jorge (Orgs.). Como renascem as democracias. São Paulo: Brasiliense, 1985. p. 104-140.

- O Brasil autoritário revisitado: o impacto das eleições sobre a Abertura. In: STEPAN, Alfred (Org.). Democratizando o Brasil. São Paulo: Paz e Terra, 1988. p. 83-134.

LESSA, Renato. Reflexões sobre a gênese de uma democracia banal. In: DINIZ, Eli; BOSCHI, Renato; LESSA, Renato. Modernização e Consolidação Democrática no Brasil: dilemas da Nova República. São Paulo: Vértice, 1989. p. 79-187.

MARENCO, André. Devagar se vai ao longe? A transição para a democracia no Brasil em perspectiva comparada. In: MELO, Carlos R.; SÁEZ, Manuel A. (Orgs.). A Democracia Brasileira. Balanço e perspectivas para o século XXI. Belo Horizonte: Humanitas, 2007. p. 73-105.

MOISÉS, José Álvaro. Os Brasileiros e a Democracia. São Paulo: Ática, 1995.

MORLINO, Leonardo. Consolidações Democráticas na Europa Meridional. Indicações teóricas para análise empírica. Dados, Rio de Janeiro, v. 35, n. 2, p. 145-172, 1992. 
NOHLEN, Dieter; THIBAUT, Bernhard. Investigación sobre la transición em América Latina: enfoques, conceptos, tesis. Heildelberg: Universidade de Heildelberg, 1994. (Arbeitspapier, 11).

NUN, José. A democracia e a modernização trinta anos depois. Lua Nova, São Paulo, n. 27, p. 31-58, dez. 1992.

O'DONNELL, Guillermo. Acerca del estado, la democratización y algunos problemas conceptuales. Una perspectiva latinoamericana com referencias a países poscomunistas. Desarollo Económico, Buenos Aires, v. 33, n. 130, p. 163-184, jul.-set. 1993.

. Delegative Democracy. Journal of Democracy, Washington, v. 5, n. 1, p. 55-69, jan. 1994.

O'DONNELL, Guillermo; SCHMITTER, Phillipe. Transições do regime autoritário: primeiras conclusões. São Paulo: Vértice, 1988.

PRZEWORSKI, Adam. Ama a incerteza e serás democrático. Novos estudos CEBRAP, São Paulo, n. 9, p. 36-46, jul. 1984.

REIS, Elisa P.; CHEIBUB, Zairo B. Pobreza, Desigualdade e Consolidação Democrática. Dados, Rio de Janeiro, v. 36, n. 2, p. 233-259, 1993.

RODRIGUES, Alberto Tosi. O Brasil de Fernando a Fernando: neoliberalismo, corrupção e protesto na política brasileira. Ijuí: Ed. Unijuí, 2001.

ROUQUIÉ, Alain. La desmilitarización y la institucionalización en América del Sur: perspectivas a partir de la década de 1970. In: O'DONNELL, Guillermo; SCHMITTER, Phillipe; WHITEHEAD, Laurence (Eds.). Transiciones desde un gobierno autoritario. Perspectivas comparadas. Barcelona: Paidós, 1994. p. 171-212.

SANTOS, Wanderley G. O Ex-Leviatã Brasileiro. Rio de Janeiro: Civilização Brasileira, 2006.

SALLUM Jr., Brasílio. Labirintos. Dos Generais à Nova República. São Paulo: Hucitec, 1996.

TRINDADE, Hélgio. Bases da democracia brasileira: lógica liberal e práxis autoritária. In: ROUQUIÉ, Alain; LAMOUNIER, Bolívar; SCHWARCZ, Jorge (Orgs.). Como renascem as democracias. São Paulo: Brasiliense, 1985. p. 4672. 


\section{ARTIGOS}

WERNECK VIANNA, Luís. Esquerda Brasileira e Tradição Republicana. Estudos de conjuntura sobre a era FHC-Lula. Rio de Janeiro: Revan, 2006.

ZAVERUCHA, Jorge. Frágil Democracia. Collor, Itamar, FHC e os Militares (1990-1998). Rio de Janeiro: Civilização Brasileira, 2000.

FHC, Forças Armadas e Polícia. Entre o autoritarismo e a democracia (1999-2002). Rio de Janeiro: Record, 2005.

Texto recebido em 15/05/2011.

Aprovado em 22/06/2011. 